\title{
Drivers' Interaction with Adaptive Cruise Control on Dry and Snowy Roads with Various Tire-Road Grip Potentials
}

\author{
Ioana Koglbauer, ${ }^{1}$ Jürgen Holzinger, ${ }^{2}$ Arno Eichberger, ${ }^{1}$ and Cornelia Lex ${ }^{1}$ \\ ${ }^{1}$ Institute of Automotive Engineering, Graz University of Technology, Graz, Austria \\ ${ }^{2}$ AVL List GmbH, Graz, Austria \\ Correspondence should be addressed to Ioana Koglbauer; i.koglbauer@gmail.com
}

Received 29 July 2016; Revised 5 October 2016; Accepted 10 October 2016; Published 12 January 2017

Academic Editor: Yuchuan Du

Copyright (c) 2017 Ioana Koglbauer et al. This is an open access article distributed under the Creative Commons Attribution License, which permits unrestricted use, distribution, and reproduction in any medium, provided the original work is properly cited.

\begin{abstract}
This study investigates drivers' interaction with Adaptive Cruise Control (ACC) in different road conditions and identifies areas of improvement. Ninety-six drivers drove with the ACC in a driving simulator showing either a summer scenery and a dry road with high grip potential or a winter scenery with a snowy road and reduced grip potential. The results show that on snowy roads the drivers set in average a lower ACC speed and preferred a larger ACC time gap. Drivers' workload and effort were higher when using the ACC on snowy as compared to dry roads. Generally, the use of a shorter ACC gap resulted in lower ratings of comfort, safety, and trust and higher ratings of mental workload and effort in both dry and snowy road conditions. The drivers judged that ACC was braking too late and maintained a too short gap to the forward vehicle, especially when the ACC was set to 1 second as compared to a 1.8-second time gap. A future adaptation of ACC's control strategy to reduced tire-road grip potential would not only improve comfort and user acceptance of the human driver but also increase the potential to react in emergency situations with braking or evasive steering.
\end{abstract}

\section{Introduction}

According to the World Health Organization [1], up to 50 million people suffer injuries and more than 1.2 million people die because of road traffic crashes each year. The use of automated driving systems is expected to reduce the number of accidents [1]. In 2011 the European Commission [2] identified the deployment of driver assistance systems as a key measure towards the reduction of accidents and improvement of road safety. Automation would have the highest accident prevention potential on roads with reduced tireroad friction coefficient (grip). However, currently available driver assistance systems fulfill the requirements of accident prevention only on dry roads with high grip. The reason for this is the general intention in development of automated driving functions to reduce the risk of false positives, that is, the initiation of active corrective measures (e.g., braking or steering) in the vehicle when it is the wrong decision. Typical examples would be a very early activation of an Automated Emergency Braking (AEB) system in dry road conditions wrongly assuming low tire-to-road grip or long distances to the target vehicle in Adaptive Cruise Control (ACC). Drivers of vehicles with frequent false positives would get annoyed and deactivate the system. The European Road Transport Research Advisory Council summarized the European roadmap towards automated driving as well as the key challenges [3]. Among eight key challenges, the first mentioned is Environmental Detection and Perception. It is pointed out that, based on the perception of multiple sensors, "[...] driving strategies need to be calculated, which take the dynamic interaction of all traffic participants into account" [3, page 30]. However the tire-to-road interface limits the possibility of driving strategies as well as the dynamics of the traffic on a physical layer and is therefore implicitly addressed. In the United States, the US Department of Transportation (DoT) published a program framework lasting for several years to initiate research and development in all automation levels of driving, which is especially related to the legal framework for testing and validation of automated vehicles [4]. 
In the United States, adverse weather was found to be a contributing factor in more than 1.5 million vehicular crashes annually $[5,6], 28 \%$ of total accidents, and almost $20 \%$ of highway fatalities $[6,7]$. There were more fatalities on the first snowy days of the year, especially in drivers older than 65 years. The study has not explicitly addressed the contribution of human error to the accidents. However, experienced drivers have been considered to drive more slowly and carefully in snowy weather and to brake earlier, thus reducing the risk of accidents. Statistical analyses of real accident data show that snowfall contributes to higher accident rates [6, 8-10]. Wallman and Åström [11] assessed how the tire-road grip potential influenced accident rates calculated as person injuries per million vehicle kilometers. They found an accident rate of $80 \%$ when the grip was lower than 0.15 , an accident rate of $55 \%$ for a grip interval of 0.15 to 0.24 , a rate of $25 \%$ for a grip between 0.25 and 0.34 , and an accident rate of $20 \%$ for a grip between 0.35 and 0.44 .

Research shows that drivers primarily adapt to snow by reducing speed. On roads with a speed limit of $90 \mathrm{~km} / \mathrm{h}$, car speeds of 85 to $95 \mathrm{~km} / \mathrm{h}$ have been reported when the road was dry, and a speed reduction of 6 to $10 \mathrm{~km} / \mathrm{h}$ has been reported when the road was covered with ice and hard snow [12]. A Finnish study compared driving speeds on dry and snowy road conditions and found a speed reduction of $0-$ $3 \mathrm{~km} / \mathrm{h}$ when the grip was between 0.35 and $0.45,3-6 \mathrm{~km} / \mathrm{h}$ for a grip between 0.25 and 0.35 , and $4-7 \mathrm{~km} / \mathrm{h}$ when the grip was less than 0.25 [13]. Kilpeläinen and Summala [14] reported a reduced mean speed by $1.6 \mathrm{~km} / \mathrm{h}$ and a longer headway in snowing weather. More detailed driving strategies on snowy roads have been investigated by Summala [15]. He showed that, in adverse weather conditions, drivers used not only lower speeds, but also longer headways and avoided overtaking other vehicles on two-lane roads. Research shows that drivers primarily adapted their driving style to the visual cues of the winter scenery and the kinesthetic cues were less important [12]. Thus, drivers use visual cues and adapt to an anticipated rather than real level of friction $[12,16]$.

The Society of Automotive Engineers (SAE International) develops standards for engineering transportation systems. In 2014 SAE has specified six levels of driving automation for on-road vehicles. Currently implemented driving functions with an automation level below SAE level 3 require drivers' monitoring of the environment and responsibility to accept or override the automated vehicle control [17]. Automated driving functions of SAE level 3 and higher must consider environmental factors such as the current road condition to prevent accidents. Thus, knowledge about drivers' interaction with automation in conditions of high and reduced grip is necessary for future improvement of automation.

This study focuses on drivers' interaction with the ACC on dry and snowy roads with high and reduced grip and fills a gap in the research on driver automation. The ACC automatically accelerates the vehicle to a speed set by the driver and decelerates to maintain a certain separation or time-to-collision gap when following a slower forward driving vehicle. The human driver is expected to perform all remaining aspects of the driving task. Thus, the driver selects the speed and the follow distance and must override the ACC, taking over control in conditions that ACC cannot deal with adequately. The use of ACC changes drivers' role from operator to supervisor of the automated longitudinal car and vehicle following control [18].

A retrospective study showed that the use of driver assistance systems would have contributed to avoid collision accidents or reduce their negative outcome, depending on the level of automation of the assistance system [19]. The retrospective study used an in-depth database of fatal road accidents for which the precollision phase starting at the conflict point could be reconstructed. The efficiency of driver assistance systems in avoiding each accident was evaluated by simulation or by expert evaluation. The five best rated systems suggested potentials to prevent fatal accidents for a Forward Collision Warning System (F-CWS) of 38\%, Driver Vigilance Monitoring (DVM) of 32\%, Lane Keeping Assist (LKA) 29\%, Evasive Maneuver Assistant (EMA) of up to $23 \%$, and Automated Emergency Braking (AEB) of 22\%. However, the adaptation of the intervention strategy of the systems FCWS, EMA, and AEB to the grip potential is essential to make use of these theoretical potential for collision avoidance or mitigation of collision severity. An extensive study of ACC performed by Xiong and Boyle [20] showed that ACC could help to avoid $57.8 \%$ of conflict events.

Driver assistance systems are expected to reduce drivers' workload, improve safety and efficiency of transportation, and make cars more attractive [21]. Drivers judged that ACC increases driving comfort and safety in a real driving experiment with maneuvers such as vehicle following at constant and variable speed, and cut-in, and overtaking on the highway [22]. Research shows benefits of ACC such as better distance keeping [23] and reduced necessity to monitor the external surroundings and manually accelerate or brake [24]. Lower mental and physical demand of the driving task makes driving less effortful and decreases the probability of human errors $[25,26]$. However, if the workload becomes too low, the driver might be too less engaged and out-of-the-loop, loosing situational awareness and increasing the potential of hazards. Excessive trust in automation and excessive reliance on automation can contribute to complacency. This is a lack of monitoring that can arise when the human serves in a backup role of a highly reliable automated system [27]. In a state of increased complacency the workload related to monitoring the process would be low and the human can be less prepared and ready to take over the control from an automated system. Knowledge about the high but not perfect reliability of an automated system is considered less likely to induce operator complacency [27].

Research has shown that ACC functions safely in the majority of cases [28]. However, inadequate control actions of the ACC have been reported in situations when cut-ins with short gaps occurred, when the deceleration of the forward vehicle was too strong [29], or when the ACC loses the target in a curve [22]. In addition, spacing and velocity errors of the ACC have been reported [30]. Thus, the drivers must be alert and monitor the ACC; otherwise the potential hazards may increase. Xiong and Boyle [20] showed that drivers' manual override of the ACC was influenced by factors such as the environment, gap setting, and speed. Longer gap settings 
were found to be more comfortable and less stressful for drivers [20, 31].

A common problem in human interaction with automation is the complacency and overreliance on automation. For example, Rudin-Brown and Parker [32] showed that drivers responded later to a detected hazard when using ACC in contrast to manual driving. The delay can be due to overreliance on automation. Drivers' delayed control action may become a safety issue, especially if the driver must override the ACC and take over the control on a slippery road where the brake efficiency is lower. A study of driver reaction to ACC failures [33] found that the partial lack of ACC deceleration has led to a collision with the lead car in $43 \%$ of the cases. Drivers can trust the ACC in some, but not in all conditions. If the drivers do not trust the ACC in all situations, their acceptance to use it will be lower. If the drivers excessively trust the ACC, they may not be alert and prepared to take over the control when required. Automation can improve drivers' situational awareness as compared to manual driving if the drivers are motivated and instructed to monitor the environment [34].

Drivers' acceptance and trust in automated assistance systems is crucial for using them. Acceptance depends on both the noticeable benefits for the user such as comfort and the fail-safe characteristics of automated systems [35]. The acceptance of the ACC is better if the automatic control actions mimic human driving behavior [36]. Therefore, automated systems need a control strategy adapted to the road condition similar to that of human drivers. Drivers' override is likely when the acceleration or deceleration rate and gap maintained by the ACC do not meet drivers' expectations. Research shows that longer gaps settings resulted in fewer mismatches in drivers' expectations [18]. However, it is possible that drivers rely too much on automation, accept acceleration rates, and tolerate gaps which are safety critical [18].

ACC may be more effective if the algorithms for gap settings and warnings included individual differences and environmental conditions [20]. Drivers' interaction with ACC was investigated in different traffic conditions $[18,22$, $28,29]$. Theoretically the greatest potential of the driver assistance systems to reduce the number of accidents would be in conditions of limited grip [37, 38]. However, few studies investigated drivers' interaction with the ACC in winter conditions with snow and reduced grip.

This study investigates how drivers' interaction with the ACC is influenced by the road condition (summer scenery, dry road with high grip $[\mu=1.0]$ versus winter scenery, and snowy road with reduced grip $[\mu=0.5]$ ). Following research hypotheses have been formulated:

(1) Based on previous research [12-15], we expect that drivers will set a slower ACC speed on snowy than on dry roads.

(2) In line with previous research on manual driving on snowy roads $[14,15]$ we expect that more drivers will estimate the ACC reaction as being similar to their own when using the longer ACC time gap $(1.8 \mathrm{sec}-$ onds) as compared to the shorter ACC gap (1 second). In addition, we hypothesize that on snowy roads more drivers will consider the control actions of the ACC with 1.8 -second gap appropriate as compared to the ACC with 1-second gap.

(3) Because drivers have to supervise the ACC and be ready to intervene, we expect that drivers' workload will be higher when driving with the ACC on snowy as compared to dry roads. In addition, drivers' selfratings of comfort, safety, and trust in ACC are expected to be lower on snowy as compared to dry roads.

(4) We expect that drivers' self-ratings of comfort [20], safety, and trust in ACC will be lower and drivers' workload will be higher [31] when driving with the shorter ACC gap (1 second) as compared to the 1.8second gap. We hypothesize that fewer drivers will find the control actions appropriate and would use the shorter ACC gap (1 second) as compared to the 1.8second gap on dry roads [22].

The rest of this paper is structured as follows. The method section describes the participants to the experiment, the driving simulator, and the procedure of the experiment, as well as the experimental design, dependent measures, and data analysis. Afterwards, the results are described and discussed in relation to the research hypotheses and research in the field. The conclusion sums up the most important results and their relevance for future development of the ACC in special and higher levels of automation in general.

\section{Method}

2.1. Participants. Ninety-six drivers (48 women) aged between 20 and 75 years with a mean age of 44 years $(\mathrm{SD}=13.65)$ participated in the study. The drivers reported a driving activity between 2,000 and $60,000 \mathrm{~km}(\mathrm{M}=18,208$, $\mathrm{SD}=10,802 \mathrm{~km})$ in the past twelve months. Automatic gear was used by $20 \%$ of the drivers whereas $80 \%$ regularly drove with manual gear and clutch. Cruise control (CC) was regularly used by $79 \%$ of drivers. Each participant was informed about the purpose and procedure of the experiment and signed an informed consent form.

2.2. Driving Simulator. The simulator is a fixed-base vehicle mock-up of a Mini Countryman. Detailed force feedback simulation includes an active steering wheel, an active brake system, passive throttle, and an automatic transmission. The visual system includes six LCD monitors, four 55-inch monitors placed outside the front wind shield, and two 23-inch monitors on each of the front side windows of the vehicle. The sound simulation was implemented with bass shakers in the vehicle's compartment and HiFi system. Engine, road, and wind noise were simulated for the ego vehicle as well as for other traffic. Configurable human machine interfaces were implemented to control and adjust the investigated vehicle systems $[39,40]$. The simulator features no motion platform. However, the pitch-down movement at the onset of braking was simulated in the visual system. Thus, the drivers could notice the onset of a braking maneuver. The summer condition used a high grip potential $(\mu=1)$ and showed a 
TABLE 1: Experimental design.

\begin{tabular}{|c|c|c|c|c|}
\hline \multirow{2}{*}{ Two blocks } & \multicolumn{2}{|c|}{ High grip potential $(\mu=1)$} & \multicolumn{2}{|c|}{ Reduced grip potential $(\mu=0.5)$} \\
\hline & \multicolumn{2}{|c|}{ Dry road, summer scenery } & \multicolumn{2}{|c|}{ Partly snowy road, winter scenery } \\
\hline ACC time gap & 1 second & 1.8 seconds & 1 second & 1.8 seconds \\
\hline Evaluation & $n$ & $n$ & $n$ & $n$ \\
\hline
\end{tabular}

completely dry road in a landscape with green grass and trees. The winter scenery used a reduced grip potential $(\mu=0.5)$ and showed a road and landscape partly covered with snow.

2.3. Procedure. All participants received a written briefing about ACC and a familiarization session with the simulator and the ACC on a dry highway with high grip. Afterwards, they drove four maneuvers with two coefficients of friction ( 1 for the summer scenery/dry road and 0.5 for the winter scenery/snowy road) and two time gaps of the ACC (1 second and 1.8 seconds).

There were two experimental blocks, one for each road condition: summer scenery with high coefficient of friction and winter scenery with reduced coefficient of friction. The presentation order of the road conditions and of the ACC gaps was counterbalanced. For each road condition and ACC gap, four maneuvers were performed in a fixed order: vehicle following at constant and variable speed, cutin, and overtaking. The selection of the driving maneuvers was a subset of a typical ACC testing carried out by vehicle manufacturers. In each road condition the drivers could select a preferred speed of the ACC between $100 \mathrm{~km} / \mathrm{h}$ and $130 \mathrm{~km} / \mathrm{h}$. The ACC control behavior was identified from a production vehicle. For that purpose we used results from previous tests on public roads [22]. The duration of the experiment was 1.5-2 hours per driver.

2.4. Dependent Measures. After each experimental block the drivers evaluated the automated control actions of the ACC according to the categories described in [22]. Thus, drivers could choose one of these categories for evaluating the reaction begin of the ACC: appropriate, too early, or too late. The strength of acceleration (and deceleration) was evaluated using the categories appropriate, too strong, and too weak. The jerk was evaluated using the categories appropriate, too weak, and too jerky. The question if the drivers would react in a similar manner as the ACC was answered with yes or no. In addition, the drivers rated their comfort, safety, and trust in the ACC system on a numerical scale ranging from 1 (very low) to 6 (very high). Subjective workload was rated using the NASA TLX questionnaire with six subscales: mental demand, physical demand, temporal demand, performance, effort, and frustration [41]. The NASA TLX numerical scales ranged from $(-5)$ very low to $(+5)$ very high. The acceptance of the ACC was rated after each maneuver block using the categories: would use the ACC for sure, maybe would use the ACC, not sure, and would not use the ACC.

2.5. Data Analysis. Analysis of variance was used to evaluate the effects of the road condition and of the ACC gap on drivers' speed selection and subjective measures of workload, comfort, safety, and trust in ACC. There were two betweensubjects factors: the road condition (dry versus snowy road) and the ACC gap (1 versus 1.8 seconds). The experimental design is presented in Table 1 . Chi-square tests were calculated for testing differences between frequencies. Data analysis followed the model of descriptive data analysis [42] and alpha was set at 0.05 .

\section{Results and Discussion}

3.1. Kinematic Data of Driving with the ACC in Different Road Conditions. As Table 2 shows, the ACC speed set by the drivers was significantly lower on the snowy road with reduced grip potential [mean $(\mathrm{M})=32.55 \mathrm{~m} / \mathrm{s}$ ] than on the dry road with high grip potential $(\mathrm{M}=35.48 \mathrm{~m} / \mathrm{s})[F(1,95)=$ 109.95, $p<0.0001$, and $\left.\eta^{2}=.54\right]$. The reduction of ACC's set speed on snowy winter roads was reported also for manual driving [12-15]. Thus, the first hypothesis was confirmed.

The kinematic data of driving with ACC in both road conditions is described in Table 2. As the ACC does not use information about the road condition, its control actions are determined by the relative speed to a forward driving vehicle. Thus, due to the lower speed set by the drivers on the snowy road with reduced grip potential, the ACC started to brake at a shorter distance to the slower forward vehicle than on the dry road. The mean deceleration and the maximal deceleration jerk of the ACC were weaker on the snowy road with reduced grip than on the dry road with high grip potential. Although the goal of ACC is to control the preset gap or time-to-collision which is constant, the distance maintained can vary. On the snowy road the ACC maintained a longer relative distance to the forward vehicle after deceleration than on the dry road. The mean acceleration and the maximal acceleration jerk of the ACC were weaker on the snowy than on the dry road. A limitation of the study that should be considered in the interpretation of these results was that the simulator featured no motion platform. Thus, acceleration cues have been simulated only visually.

There was a significant effect of the age group on the ACC speed set by the drivers $[F(4,86)=6.78, p<0.0001$, and $\left.\eta^{2}=.24\right]$. The Tukey-HSD post hoc procedure for pairwise comparisons between groups showed that the age group 6075 selected a slower ACC speed than the groups 20-29 years $(p<0.005)$ and $30-39$ years $(p<0.0001)$. The group $40-49$ years selected a slower ACC speed than the group 30-39 years $(p<0.008)$. Other differences between the age groups did not reach significance. There was no significant correlation between the driving activity in the past year and the ACC set speed. However, the results of this study confirm previous 
TABLE 2: Kinematic data of driving with ACC in both road conditions $(N=96)$.

\begin{tabular}{|c|c|c|c|c|c|}
\hline \multirow{2}{*}{ Kinematic variable } & \multirow{2}{*}{$\begin{array}{l}\text { Scenery and } \\
\text { grip potential }\end{array}$} & \multirow{2}{*}{ Mean $(\mathrm{M})$} & \multirow{2}{*}{$\begin{array}{c}\text { Standard } \\
\text { deviation (SD) }\end{array}$} & \multicolumn{2}{|c|}{ 95\% confidence interval } \\
\hline & & & & Lower limit & Upper limit \\
\hline \multirow{2}{*}{ Speed set by the driver $(\mathrm{m} / \mathrm{s})$} & Summer $(\mu=1)$ & 35.48 & 0.17 & 35.14 & 35.82 \\
\hline & Winter $(\mu=0.5)$ & 32.55 & 0.30 & 31.97 & 33.14 \\
\hline \multirow{2}{*}{ Distance gap at begin of the ACC reaction (m) } & Summer $(\mu=1)$ & 179.78 & 1.80 & 176.20 & 183.35 \\
\hline & Winter $(\mu=0.5)$ & 169.40 & 1.87 & 165.68 & 173.12 \\
\hline \multirow{2}{*}{ Mean deceleration of the ACC $\left(\mathrm{m} / \mathrm{s}^{2}\right)$} & Summer $(\mu=1)$ & -0.84 & 0.01 & -0.85 & -0.82 \\
\hline & Winter $(\mu=0.5)$ & -0.72 & 0.01 & -0.74 & -0.70 \\
\hline \multirow{2}{*}{ Maximal jerk of the ACC deceleration $\left(\mathrm{m} / \mathrm{s}^{3}\right)$} & Summer $(\mu=1)$ & 11.14 & 0.45 & 10.25 & 12.03 \\
\hline & Winter $(\mu=0.5)$ & 8.53 & 0.40 & 7.74 & 9.31 \\
\hline \multirow{2}{*}{ Mean acceleration of the ACC $\left(\mathrm{m} / \mathrm{s}^{2}\right)$} & Summer $(\mu=1)$ & 0.51 & 0.004 & 0.50 & 0.51 \\
\hline & Winter $(\mu=0.5)$ & 0.48 & 0.01 & 0.47 & 0.49 \\
\hline \multirow{2}{*}{ Maximal jerk of the ACC acceleration $\left(\mathrm{m} / \mathrm{s}^{3}\right)$} & Summer $(\mu=1)$ & 5.30 & 0.26 & 4.78 & 5.82 \\
\hline & Winter $(\mu=0.5)$ & 3.86 & 0.17 & 3.52 & 4.21 \\
\hline \multirow{2}{*}{ Distance gap after the ACC reaction (m) } & Summer $(\mu=1)$ & 34.38 & 0.16 & 34.07 & 34.69 \\
\hline & Winter $(\mu=0.5)$ & 35.13 & 0.19 & 34.75 & 35.51 \\
\hline
\end{tabular}

Note: m: meter; s: second.

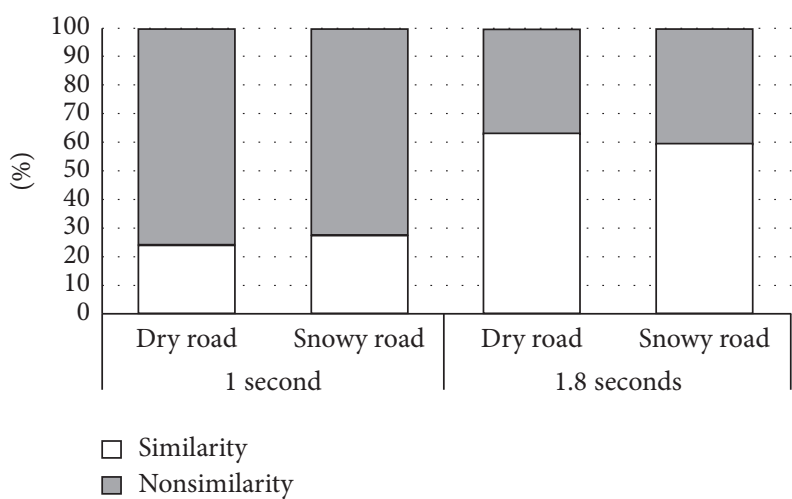

FIGURE 1: Drivers' reported reaction similarity compared with the Adaptive Cruise Control.

findings that experienced drivers drive more slowly in snowy weather [6].

3.2. Reaction Similarity and Appropriateness of ACC Gap Settings on Snowy Roads with Reduced Grip. Drivers' evaluation of the ACC's control actions on snowy roads with reduced grip potential was analyzed for two standard gap settings (1 and 1.8 seconds). As Figure 1 shows, on snowy roads significantly more drivers reported that they would react in a similar manner as the ACC with the longer as compared to the shorter gap setting $\left[\chi^{2}(\mathrm{df}=1, N=96)=5.79\right.$; $p<0.025]$.

Significantly more drivers considered the headway of the 1.8 seconds ACC time gap appropriate as compared to the 1second gap on snowy roads $\left[\chi^{2}(\mathrm{df}=1, N=96)=30.22\right.$; $p<0.001]$. Fewer drivers considered the timeliness of ACC deceleration appropriate with the shorter than with the longer ACC gap $\left[\chi^{2}(\mathrm{df}=1, N=96)=6.22 ; p<0.025\right]$.
Noteworthy, on snowy roads more drivers (52\%) considered that the ACC with the gap of 1 second decelerated too late as compared to the ACC time gap of 1.8 seconds $(23 \%)$. The differences were statistically significant $\left[\chi^{2}(\mathrm{df}=1, N=96)=\right.$ 5.44; $p<0.025]$. As acceleration cues have been simulated only visually, these results should be interpreted with caution.

Furthermore, fewer drivers considered the distance gap maintained by the ACC appropriate with the shorter than with the longer ACC gap on snowy roads $\left[\chi^{2}(\mathrm{df}=1, N=96)\right.$ $=30.22 ; p<0.001$, resp.]. More drivers considered that the headway maintained by the ACC with the gap of 1 second was too short on snow (88\%) as compared to the ACC time gap of 1.8 seconds (38\%). The differences were statistically significant $\left[\chi^{2}(\mathrm{df}=1, N=96)=9.60 ; p<0.005\right]$. The timeliness of acceleration and the strength and jerk of both deceleration and acceleration were considered appropriate by most of the drivers. As illustrated in Figure 2, fewer drivers would accept to use the ACC with the shorter gap in snowy road conditions $\left[\chi^{2}(\mathrm{df}=1, N=96)=10.24 ; p<0.005\right]$. Thus, the second research hypothesis was confirmed.

These findings are in line with research on nonautomatic driving showing that drivers maintain a longer gap on snowy roads $[14,15]$. The results presented in this study are based on a more detailed analysis of automated control actions and show areas of improvement driving automation on snowy roads with reduced tire-road grip potential. Drivers' preference for an earlier ACC braking reaction and a longer ACC gap on snowy roads could be explained by the need of a time or safety buffer when using and supervising the ACC. If drivers expect the ACC to control a time-to-collision gap of 1 second and the ACC fails, then the time left for the human to take over the control and brake might not be enough for avoiding a hazard. Thus, the gap preference of the drivers might be influenced not only by the road condition, but also by the interaction with the ACC. Thus, these results should be 


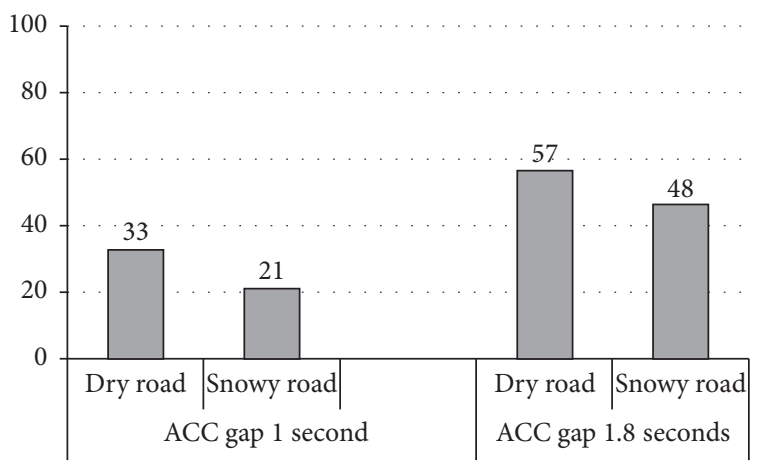

FIGURE 2: Acceptance ratings of the ACC gaps in different road conditions. Data is presented in percentage.

interpreted with caution keeping in mind that the simulator had no motion platform and the drivers could notice the onset of a braking maneuver only visually. The pitch-down movement at the onset of braking was simulated in the visual system.

3.3. Drivers' Self-Ratings of Workload, Comfort, Trust, and Safety in Different Road Conditions. The results show that automated driving on the snowy road with reduced grip was rated as more mentally, physically and temporally demanding than driving on a dry road with high grip potential $[F(1,95)=$ 6.40, $p<0.01$, and $\eta^{2}=.06 ; F(1,95)=7.88, p<0.006$, and $\eta^{2}=.08$; and $F(1,95)=4.70, p<0.03$, and $\eta^{2}=.05$, resp.]. Table 3 shows the means, standard errors, and the $95 \%$ confidence intervals for subjective ratings of the drivers in both road conditions. Drivers' ratings of safety and trust in the ACC were lower in the snowy road condition, but differences failed the statistical significance level of $0.05[F(1,95)=$ 3.67, $p<0.058$, and $\eta^{2}=.04$ and $F(1,95)=3.17, p<$ 0.078 , and $\eta^{2}=.03$, resp.]. The effect of the road condition on drivers' ratings of performance, frustration, and comfort did not reach statistical significance. Thus, the third research hypothesis was only partially confirmed. Although drivers' subjective feeling of safety and trust was not significantly diminished when driving with the ACC on snowy roads with reduced grip, the supervision of the ACC on snowy roads was more demanding and the drivers spent more effort than on dry roads with high grip. The drivers reported higher effort when ACC was driving on snowy as compared to dry roads $\left[F(1,95)=8.10, p<0.005\right.$, and $\left.\eta^{2}=.08\right]$. There was a significant but small effect of the age group on the ratings of mental workload $\left[F(4,86)=2.62, p<0.04\right.$, and $\left.\eta^{2}=.11\right]$, temporal demand $\left[F(4,86)=2.61, p<0.04\right.$, and $\left.\eta^{2}=.11\right]$, effort $\left[F(4,86)=3.28, p<0.02\right.$, and $\left.\eta^{2}=.13\right]$, and trust $[F(4,86)=$ $2.83, p<0.03$, and $\left.\eta^{2}=.12\right]$. However, the Tukey-HSD post hoc procedure for pairwise comparisons confirmed group differences only for trust. Trust in the ACC was significantly lower in the group 20-29 than in the group 50-59 ( $p<0.05)$. Other differences between the age groups did not reach significance. When interpreting these results within the perspective of human-centered automation [27] a higher workload when driving with the ACC on snowy roads with reduced grip potential than on dry roads with high grip does not seem to be inappropriate. Mental concentration on the driving situation and readiness to quickly take over the control of the car are adaptive preparatory responses of the drivers.

3.4. Effects of the ACC Gap. The ACC gap had a significant effect on drivers' ratings of mental demand $[F(1,95)=14.37$, $p<0.0001$, and $\left.\eta^{2}=.13\right]$, effort $[F(1,95)=5.60, p<0.02$, and $\left.\eta^{2}=.06\right]$, frustration $[F(1,95)=10.85, p<0.001$, and $\left.\eta^{2}=.10\right]$, comfort $[F(1,95)=27.01, p<0.0001$, and $\left.\eta^{2}=.22\right]$, safety $\left[F(1,95)=52.07, p<0.0001\right.$, and $\left.\eta^{2}=.35\right]$, and trust $\left[F(1,95)=29.19, p<0.0001\right.$, and $\left.\eta^{2}=.24\right]$. As Table 4 shows, driving with the ACC gap of 1 second was associated with higher mental demand, effort, and frustration than driving with the gap of 1.8 seconds independent of the road conditions. There was a significant negative correlation between the driving activity in the past year $(\mathrm{km} /$ year) and the ratings of mental demand only in the dry condition $(r=$ $-0.23, p<0.03$, and $N=96$ with the 1.8 -second gap and $r=-0.26, p<0.01$, and $N=96$ with the 1-second gap). The negative correlation between the driving activity in the past year and the ratings of temporal demand in the dry road condition approached statistical significance only for the 1second gap $(r=-0.22, p<0.03$, and $N=96)$. In winter conditions the positive correlation between the driving activity $(\mathrm{km} /$ year $)$ and the ratings of safety approached statistical significance only for the 1 -second gap $(r=0.21, p<0.04$, and $N=96$ ). These results confirm previous findings that drivers experience a higher workload when using a shorter ACC gap [31]. The results show that reduced driving activity in the past year is associated with higher mental demand and temporal demand and lower safety ratings. Drivers' ratings of comfort were lower with the shorter ACC confirming the results of Xiong and Boyle [20]. In addition, drivers' ratings of safety and trust were lower with the ACC gap of 1 second. Gap effects on drivers' ratings of physical and temporal demand and performance did not reach statistical significance.

Noteworthy, the results show that $96 \%$ of drivers reported a preference for the 1.8-second gap of the ACC, whereas $4 \%$ had a preference for the 1-second gap. Even on dry roads fewer drivers would use the ACC with the 1-second gap as compared to the 1.8-second gap $\left[\chi^{2}(\mathrm{df}=1, N=96)=6.08\right.$; $p<0.025]$. A more detailed analysis of the ACC's control actions shows that fewer drivers considered the timeliness of ACC deceleration at 1-second gap appropriate $\left[\chi^{2}(\mathrm{df}=1\right.$, $N=96)=9.80 ; p<0.005]$. On dry roads more drivers considered that the ACC with the gap of 1 second decelerated too late $(58 \%)$ as compared to the ACC time gap of 1.8 seconds (20\%). The differences reached statistical significance $\left[\chi^{2}(\mathrm{df}=1, N=96)=18.25 ; p<0.001\right]$. On dry roads fewer drivers considered the headway appropriate with the ACC's 1-second gap as compared to the 1.8-second gap [ $\chi^{2}$ $(\mathrm{df}=1, N=96)=25.98, p<0.001]$. An aspect criticized by the drivers was the too short headway maintained by the ACC with the gap of 1 second (80\%) as compared to the ACC time gap of 1.8 seconds $(21 \%)$ on dry roads. The differences reached statistical significance $\left[\chi^{2}(\mathrm{df}=1, N=\right.$ 96) $=33.49, p<0.001]$. The timeliness of acceleration and 
TABLE 3: Drivers' self-ratings of workload, comfort, safety, and trust related to driving with the ACC on dry and snowy roads with various grip potentials $(N=96)$.

\begin{tabular}{|c|c|c|c|c|c|}
\hline \multirow{2}{*}{ Subjective variable } & \multirow{2}{*}{$\begin{array}{l}\text { Road condition and } \\
\text { grip potential }\end{array}$} & \multirow{2}{*}{ Mean } & \multirow{2}{*}{$\begin{array}{l}\text { Standard } \\
\text { deviation }\end{array}$} & \multicolumn{2}{|c|}{ 95\% confidence interval } \\
\hline & & & & Lower limit & Upper limit \\
\hline \multirow{2}{*}{ Mental Demand } & $\operatorname{Dry}(\mu=1)$ & -2.85 & 0.22 & -3.28 & -2.42 \\
\hline & Snow $(\mu=0.5)$ & -2.46 & 0.25 & -2.96 & -1.96 \\
\hline \multirow{2}{*}{ Physical Demand } & $\operatorname{Dry}(\mu=1)$ & -3.33 & 0.20 & -3.72 & -2.94 \\
\hline & Snow $(\mu=0.5)$ & -3.07 & 0.22 & -3.51 & -2.64 \\
\hline \multirow{2}{*}{ Temporal Demand } & $\operatorname{Dry}(\mu=1)$ & -3.36 & 0.19 & -3.74 & -2.98 \\
\hline & Snow $(\mu=0.5)$ & -3.07 & 0.22 & -3.49 & -2.64 \\
\hline \multirow{2}{*}{ Performance } & $\operatorname{Dry}(\mu=1)$ & 2.39 & 0.28 & 1.85 & 2.94 \\
\hline & Snow $(\mu=0.5)$ & 2.23 & 0.26 & 1.72 & 2.75 \\
\hline \multirow{2}{*}{ Effort } & $\operatorname{Dry}(\mu=1)$ & -2.93 & 0.23 & -3.39 & -2.46 \\
\hline & Snow $(\mu=0.5)$ & -2.45 & 0.25 & -2.94 & -1.96 \\
\hline \multirow{2}{*}{ Frustration } & $\operatorname{Dry}(\mu=1)$ & -3.23 & 0.23 & -3.69 & -2.78 \\
\hline & Snow $(\mu=0.5)$ & -3.10 & 0.23 & -3.55 & -2.65 \\
\hline \multirow{2}{*}{ Comfort } & $\operatorname{Dry}(\mu=1)$ & 4.88 & 0.11 & 4.67 & 5.09 \\
\hline & Snow $(\mu=0.5)$ & 4.85 & 0.11 & 4.63 & 5.07 \\
\hline \multirow{2}{*}{ Safety } & Dry $(\mu=1)$ & 4.63 & 0.12 & 4.38 & 4.87 \\
\hline & Snow $(\mu=0.5)$ & 4.47 & 0.13 & 4.21 & 4.73 \\
\hline \multirow{2}{*}{ Trust } & $\operatorname{Dry}(\mu=1)$ & 4.51 & 0.13 & 4.25 & 4.76 \\
\hline & Snow $(\mu=0.5)$ & 4.38 & 0.14 & 4.11 & 4.65 \\
\hline
\end{tabular}

Note: ranges of the scales are specified in Section 2.4.

the strength and jerk of both deceleration and acceleration were considered appropriate by most of the drivers. Thus, the fourth research hypothesis was partly confirmed. However, as the acceleration cues have been simulated only visually, these results should be interpreted with caution.

\section{Conclusion and Practical Implications}

In drawing the conclusions of this study several limitations should be considered. The conclusions of this paper are due to the grip and the visual scenery of summer or winter. The study used a reduced grip potential of 0.5 for the winter road partly covered with snow, but in winter even lower grip potentials can be experienced, as described in [11]. For lower grip potential another system behavior can be expected. The acceleration cues were simulated only visually. The simulator featured no full-motion platform.

The main findings show that drivers' speed reduction of the ACC on snowy roads partially helped the ACC to adapt its control strategy to reduced tire-road grip (e.g., weaker acceleration and jerk; longer relative distance to the forward vehicle as compared to dry roads). However, on snowy roads the ACC started to brake at a shorter distance to the slower forward vehicle than on the dry road. The acceleration and jerk of the ACC were considered appropriate by most of the drivers. However, drivers considered that ACC brakes too late and maintains a too short headway, especially with the gap of 1 second. This fact was observed and criticized by the human drivers in their evaluation of the ACC. Notwithstanding that a better adaptation of driver assistance systems to conditions of reduced grip could be achieved with an earlier braking reaction and longer headway to a slower forward vehicle, the reader should keep in mind the limitation of the simulator which had no motion platform and simulated the braking only visually. An adaptation of the ACC to conditions of reduced tire-road grip is expected to improve drivers' acceptance of the ACC. As anticipation based on visual cues has been found most important for the adaptation of humans' driving strategy $[12,16]$ the use of image processing equipment and the use of human inputs and setting selection could be included for enabling the adaptation of the ACC to snowy road conditions with reduced grip potential.

Various technological innovations have been considered for the future collection and dissemination of information about the weather and the road condition [5]. The drivers and automated driver assistance systems could use information from a road weather system [5] that includes a data collection network with sensors embedded in the roadway, video monitoring devices, Global Positioning System (GPS) information, geographical information, models, predictions, and rules of practice. Thus, the drivers and the automated systems in the vehicles could receive information about the road condition and could take decisions on when to slow down and when to change to a better route. This could contribute to the design of automated driving functions of SAE level 3 and higher that must monitor and consider the current road condition [17].

Driving automation is expected to reduce drivers' workload, improve safety, and make cars more attractive [21]. This study shows that driving with ACC on snowy winter roads was more demanding and effortful for the human drivers, but 
TABLE 4: Drivers' self-ratings of workload, comfort, safety, and trust related to driving with different time gaps of the ACC $(N=96)$.

\begin{tabular}{|c|c|c|c|c|c|}
\hline \multirow{2}{*}{ Subjective variable } & \multirow{2}{*}{ ACC GAP } & \multirow{2}{*}{ Mean } & \multirow{2}{*}{ SD } & \multicolumn{2}{|c|}{$95 \%$ confidence interval } \\
\hline & & & & Lower limit & Upper limit \\
\hline \multirow{2}{*}{ Mental Demand } & 1 second & -2.48 & 0.23 & -2.94 & -2.03 \\
\hline & 1.8 seconds & -2.82 & 0.23 & -3.27 & -2.38 \\
\hline \multirow{2}{*}{ Physical Demand } & 1 second & -3.16 & 0.21 & -3.58 & -2.75 \\
\hline & 1.8 seconds & -3.25 & 0.20 & -3.65 & -2.85 \\
\hline \multirow{2}{*}{ Temporal Demand } & 1 second & -3.13 & 0.20 & -3.52 & -2.73 \\
\hline & 1.8 seconds & -3.30 & 0.20 & -3.70 & -2.91 \\
\hline \multirow{2}{*}{ Performance } & 1 second & 2.33 & 0.25 & 1.84 & 2.83 \\
\hline & 1.8 seconds & 2.29 & 0.28 & 1.74 & 2.84 \\
\hline \multirow{2}{*}{ Effort } & 1 second & -2.54 & 0.24 & -3.01 & -2.06 \\
\hline & 1.8 seconds & -2.84 & 0.23 & -3.30 & -2.38 \\
\hline \multirow{2}{*}{ Frustration } & 1 second & -2.92 & 0.25 & -3.42 & -2.43 \\
\hline & 1.8 seconds & -3.41 & 0.20 & -3.81 & -3.01 \\
\hline \multirow{2}{*}{ Comfort } & 1 second & 4.64 & 0.12 & 4.40 & 4.88 \\
\hline & 1.8 seconds & 5.09 & 0.10 & 4.89 & 5.26 \\
\hline \multirow{2}{*}{ Safety } & 1 second & 4.14 & 0.15 & 3.85 & 4.43 \\
\hline & 1.8 seconds & 4.95 & 0.12 & 4.72 & 5.18 \\
\hline \multirow{2}{*}{ Trust } & 1 second & 4.17 & 0.15 & 3.87 & 4.46 \\
\hline & 1.8 seconds & 4.72 & 0.12 & 4.48 & 4.96 \\
\hline
\end{tabular}

Note: ranges of the scales are specified in Section 2.4.

their subjective feeling of comfort, safety, and trust was not significantly diminished as compared to the dry road conditions. Lower mental demand of the driving task is desirable as it makes driving less effortful and decreases the probability of human errors $[25,26]$. However, in this experiment the scores of mental, physical, temporal demand and effort were in the lower range of the scale, and the increase on snowy roads seems adequate as the driver has to supervise the control actions of the ACC and be prepared to override it. If the workload becomes too low, the driver might lose situational awareness. Additional information on the effect of driving with ACC on drivers' workload could be obtained by a future study with a control condition of manual driving.

Results show that $96 \%$ of drivers preferred the 1.8 -second gap of the ACC. The drivers considered that the ACC with the gap of 1 second decelerates too late and maintains a too short distance gap to the forward vehicle on both dry and snowy roads. The ACC gap of 1.8 seconds found larger acceptance, but there was still a considerable percentage of drivers who stated that the ACC decelerated too late and maintained a too short headway to the forward vehicle on both dry and snowy roads. Independent of the road condition, drivers evaluated the interaction with the ACC at the 1-second gap as more mentally demanding, effortful, and frustrating as at the larger ACC gap. The drivers felt less comfortable, safe, and trusted less the ACC with the 1-second gap. Previous findings show also that longer gap settings were more comfortable and less stressful $[20,31]$ and matched better drivers' expectations [18] than shorter gaps. According to these results, the ACC could be improved by providing and testing a broader range of gap settings which should include larger gaps.

We do not know how drivers adapt over time to the use of automation in conditions of reduced grip, but it is possible that they will rely too much on the ACC and tolerate gaps which are safety critical [18] and lose situational awareness [34]. Future research should address issues like training and instruction as well as experience effects on drivers' interaction with the ACC in conditions of high and reduced grip. Individual differences as well as cultural and regional aspects should also be included in future evaluations. An ACC that adapts its control strategy to the tire-road grip potential would not only improve comfort and user acceptance of the human driver but also increase road safety. In that case the potential to react in emergency situations would be increased, allowing the human driver or an automated driving system to react with braking or evasive steering.

In conclusion, this study shows the importance of a systematic approach for investigating interactions among drivers, automation, and environment that can be used for the future development and evaluation of ACC and other driver assistance systems. The method used in this study for the evaluation of kinematic and subjective measures can be used in future studies on drivers' interaction with automation. Future studies should use a full-motion simulator and add a condition of manual driving in both summer and winter conditions. The grip potential in winter conditions could be varied. 


\section{Competing Interests}

The authors declare that they have no competing interests.

\section{Acknowledgments}

The authors would like to thank the Austrian Federal Ministry for Transportation, Innovation, and Technology and the Austrian Research Promotion Agency (FFG), FEMtech Program Talents, Graz University of Technology, AVL List $\mathrm{GmbH}$, Fraunhofer Austria Research GmbH, and SBW Technology LTD for cofunding and realization of the project MueGen Driving (FFG no. 3413253). The authors are indebted to all drivers who participated in the experiment.

\section{References}

[1] WHO World Health Organization, Global Status Report on Road Safety, WHO, Geneva, Switzerland, 2015.

[2] European Commission, Roadmap to a Single European Transport Area-Towards a Competitive and Resource Efficient Transport System, Office for Official Publications of the European Commission. White Paper COM, Brüssel, Belgium, 2011.

[3] European Road Transport Research Advisory Council, Automated Driving Roadmap, http://www.ertrac.org/uploads/ documentsearch/id38/ERTRAC_Automated-Driving-2015.pdf.

[4] U.S. Department of Transportation (DoT), Federal Automated Vehicles Policy, Accelerating the Next Revolution in Roadway Safety, September 2016, http://www.nhtsa.gov/nhtsa/ av/av-policy.html.

[5] National Research Council, Where the Weather Meets the Road, National Academies Press, Washington, DC, USA, 2004.

[6] D. Eisenberg and K. E. Warner, "Effects of snowfalls on motor vehicle collisions, injuries, and fatalities," American Journal of Public Health, vol. 95, no. 1, pp. 120-124, 2005.

[7] American Meteorological Society, Weather and Highways: Report of a Policy Forum, American Meteorological Society, Washington, DC, USA, 2004.

[8] V. Shankar, F. Mannering, and W. Barfield, "Effect of roadway geometrics and environmental-factors on rural freeway accident frequencies," Accident Analysis and Prevention, vol. 27, no. 3, pp. 371-389, 1995.

[9] A. J. Khattak and K. K. Knapp, "Snow event effects on interstate highway crashes," Journal of Cold Regions Engineering, vol. 15, no. 4, pp. 219-230, 2001.

[10] J. Andrey, B. Mills, M. Leahy, and J. Suggett, "Weather as a chronic hazard for road transportation in Canadian cities," Natural Hazards, vol. 28, no. 2-3, pp. 319-343, 2003.

[11] C.-G. Wallman and H. Åström, "Friction measurement methods and the correlation between road friction and traffic safety," VTI Meddelande 911A-2001, Swedish National Road and Transport Research Institute, Linköping, Sweden, 2001.

[12] C.-G. Wallman, Driver Behavior on Winter Roads. VTI Rapport 419A-1997, Swedish National Road and Transport Research Institute, Linköping, Sweden, 1997.

[13] K. Saastamoinen, "Effect of road conditions on driving behavior and properties of traffic flow," FinnRA Reports 80/1993, Finnish Road Administration, Helsinki, Finland, 1993.

[14] M. Kilpeläinen and H. Summala, "Effects of weather and weather forecasts on driver behaviour," Transportation Research
Part F: Traffic Psychology and Behaviour, vol. 10, no. 4, pp. 288 299, 2007.

[15] H. Summala, "Accident risk and driver behaviour," Safety Science, vol. 22, no. 1-3, pp. 103-117, 1996.

[16] G. Öberg, "Effekter av sandning," VTI Rapport 164, 1978.

[17] SAE International, "Taxonomy and definitions for terms related to on-road motor vehicle automated driving systems," Technical Standard of Society of Automotive Engineers J3016-201401, SAE International, 2014.

[18] P. Zheng and M. McDonald, "Manual vs. adaptive cruise control-can driver's expectation be matched?" Transportation Research Part C: Emerging Technologies, vol. 13, no. 5-6, pp. 421431, 2005.

[19] A. Eichberger, E. Tomasch, R. Rohm, H. Steffan, and W. Hirschberg, "Detailed analysis of the benefit of different traffic safety systems in fatal accidents," in Proceedings of the 19th Annual EVU Congress, pp. 301-315, Prague, Czech Republic, 2010.

[20] H. Xiong and L. N. Boyle, "Drivers' adaptation to adaptive cruise control: examination of automatic and manual braking," IEEE Transactions on Intelligent Transportation Systems, vol. 13, no. 3, pp. 1468-1473, 2012.

[21] M. Vollrath and J. Krems, Verkehrspsychologie, Kohlhammer, Stuttgart, Germany, 2011.

[22] I. Koglbauer, A. Eichberger, C. Lex et al., "Bewertung von Fahrerassistenzsystemen von nicht professionellen Fahrerinnen und Fahrern im Realversuch," in Humanwissenschaftliche Beiträge zur Verkehrssicherheit und Ökologie des Verkehrs, C. ChaloupkaRisser and R. Risser, Eds., pp. 86-102, INFAR, Salzburg, Austria, 2015.

[23] M. Minderhoud and P. H. L. Bovy, "Impact of intelligent cruise control strategies and equipment rate on road capacity," in Proceedings of the 5th Annual World Congress, ITS, Seoul, South Korea, 1998.

[24] M. S. Young and N. A. Stanton, "Taking the load off: investigations of how adaptive cruise control affects mental workload," Ergonomics, vol. 47, no. 9, pp. 1014-1035, 2004.

[25] M. Hoedemaeker and K. A. Brookhuis, "Behavioural adaptation to driving with an adaptive cruise control (ACC)," Transportation Research Part F: Traffic Psychology and Behaviour, vol. 1, no. 2, pp. 95-106, 1998.

[26] N. A. Stanton and P. Marsden, "From fly-by-wire to driveby-wire: safety implications of automation in vehicles," Safety Science, vol. 24, no. 1, pp. 35-49, 1996.

[27] R. Parasuraman, R. Molloy, and I. L. Singh, "Performance consequences of automation-induced 'Complacency", The International Journal of Aviation Psychology, vol. 3, no. 1, pp. 1-23, 2009.

[28] S. McLaughlin and C. Serafin, "Measurement of driver intervention responses during transition from ACC deceleration to manual control," in Proceedings of the ITS, America Conference, Washington, DC, USA, 1999.

[29] G. Marsden, M. Brackstone, and M. McDonald, "Assessment of the stop-and-go function using real driving behaviour," in Proceedings of the ADAS Conference, pp. 76-80, Birmingham, UK, 2001.

[30] L. Xiao and F. Gao, "Practical string stability of platoon of adaptive cruise control vehicles," IEEE Transactions on Intelligent Transportation Systems, vol. 12, no. 4, pp. 1184-1194, 2011.

[31] M. Hoedemaeker, "Driving with intelligent vehicles: driving behavior with ACC and the acceptance by individual drivers," in Proceedings of the IEEE Intelligent Transportation Systems, pp. 506-509, Dearborn, Mich, USA, 2000. 
[32] C. M. Rudin-Brown and H. A. Parker, "Behavioural adaptation to adaptive cruise control (ACC): implications for preventive strategies," Transportation Research Part F: Traffic Psychology and Behaviour, vol. 7, no. 2, pp. 59-76, 2004.

[33] J. Nilsson, N. Strand, P. Falcone, and J. Vinter, "Driver performance in the presence of adaptive cruise control related failures: implications for safety analysis and fault tolerance," in Proceedings of the 2013 43rd Annual IEEE/IFIP Conference on Dependable Systems and Networks Workshop (DSN-W '13), pp. 1-10, Budapest, Hungary, June 2013.

[34] J. C. F. De Winter, R. Happee, M. H. Martens, and N. A. Stanton, "Effects of adaptive cruise control and highly automated driving on workload and situation awareness: a review of the empirical evidence," Transportation Research Part F: Traffic Psychology and Behaviour, vol. 27, pp. 196-217, 2014.

[35] K. A. Brookhuis, D. De Waard, and W. H. Janssen, "Behavioural impacts of advanced driver assistance systems-an overview," European Journal of Transport and Infrastructure Research, vol. 1, no. 3, pp. 245-253, 2001.

[36] C. J. G. Van Driel, M. Hoedemaeker, and B. van Arem, "Impacts of a congestion assistant on driving behavior and acceptance using a driving simulator," Journal of Transportation Research F, vol. 10, no. 2, pp. 139-152, 2007.

[37] C. Lex, A. E. Rojas Rojas, H. Niederkofler, and A. Eichberger, "Evaluation of the potential of active powertrain, braking and steering systems based on in wheel motors to improve the effectiveness of an evasive manoeuvre assistant," International Journal of Powertrains, vol. 2, no. 2-3, pp. 132-152, 2013.

[38] H. Niederkofler, C. Lex, A. Eichberger, and A. E. Rojas Rojas, "Potentialanalyse von aktiven fahrwerks- und antriebssystemen für die anwendung in fahrerassistenzsystemen in kritischen fahrsituationen," in Proceedings of the 13th VDI-Tagung ReifenFahrbahn-Fahrwerk, pp. 337-343, Hannover, Germany, 2011.

[39] C. Lex, D. Hammer, M. Pirstinger et al., "Multidisciplinary development of a driving simulator with autostereoscopic visualization for the integrated development of driver assistance systems," in Proceedings of the HORIBA CONCEPT, Conference for Combustion, Emissions, Particulates and Testing, Dresden, Germany, 2015.

[40] C. Schinko, M. Peer, D. Hammer et al., "Building a driving simulator with parallax barrier displays," in Proceedings of the 11th International Joint Conference on Computer Vision, Imaging and Computer Graphics Theory and Applications, pp. 283-291, Rome, Italy, 2016.

[41] S. G. Hart and L. E. Staveland, "Development of NASATLX (Task Load Index): results of empirical and theoretical research," in Human Mental Workload, P. A. Handcock and N. Meshkati, Eds., pp. 139-183, Elsevier Science, Amsterdam, The Netherlands, 1988.

[42] K. Abt, "Descriptive data analysis: a concept between confirmatory and exploratory data analysis," Methods of Information in Medicine, vol. 26, no. 2, pp. 77-88, 1987. 


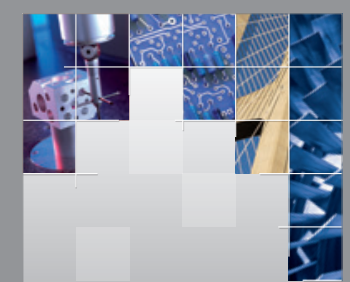

\section{Enfincering}
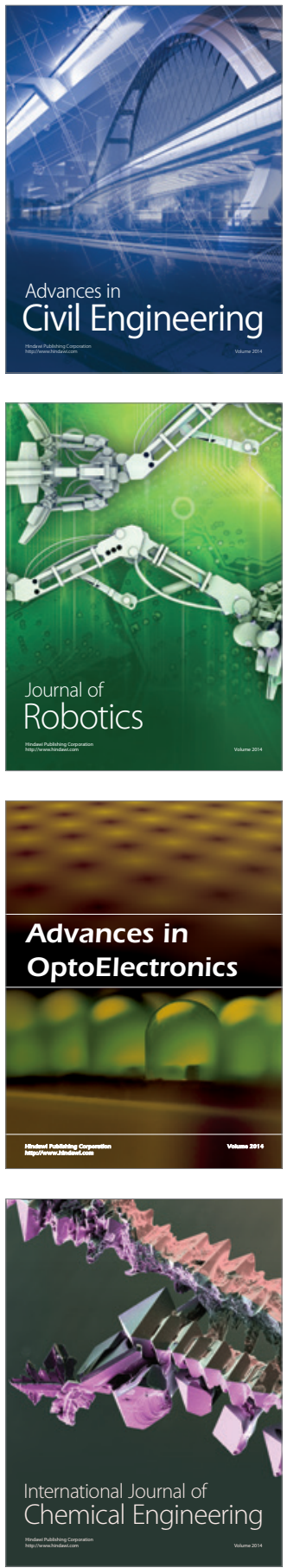

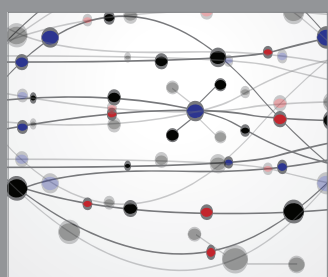

The Scientific World Journal

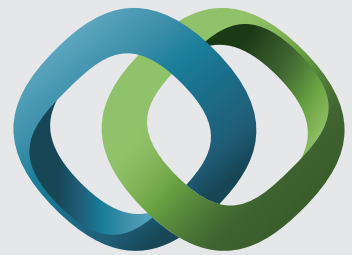

\section{Hindawi}

Submit your manuscripts at

https://www.hindawi.com
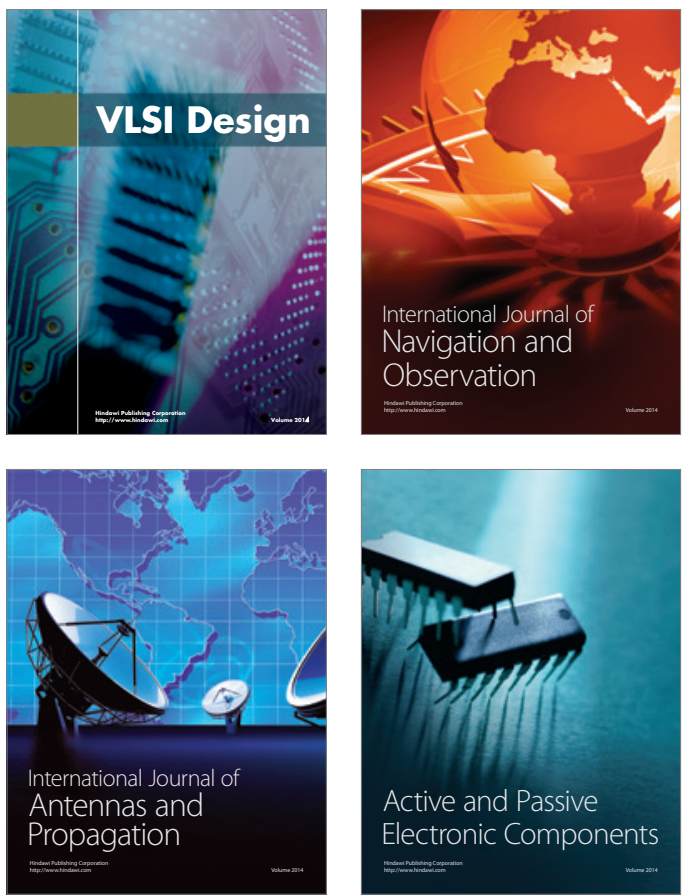
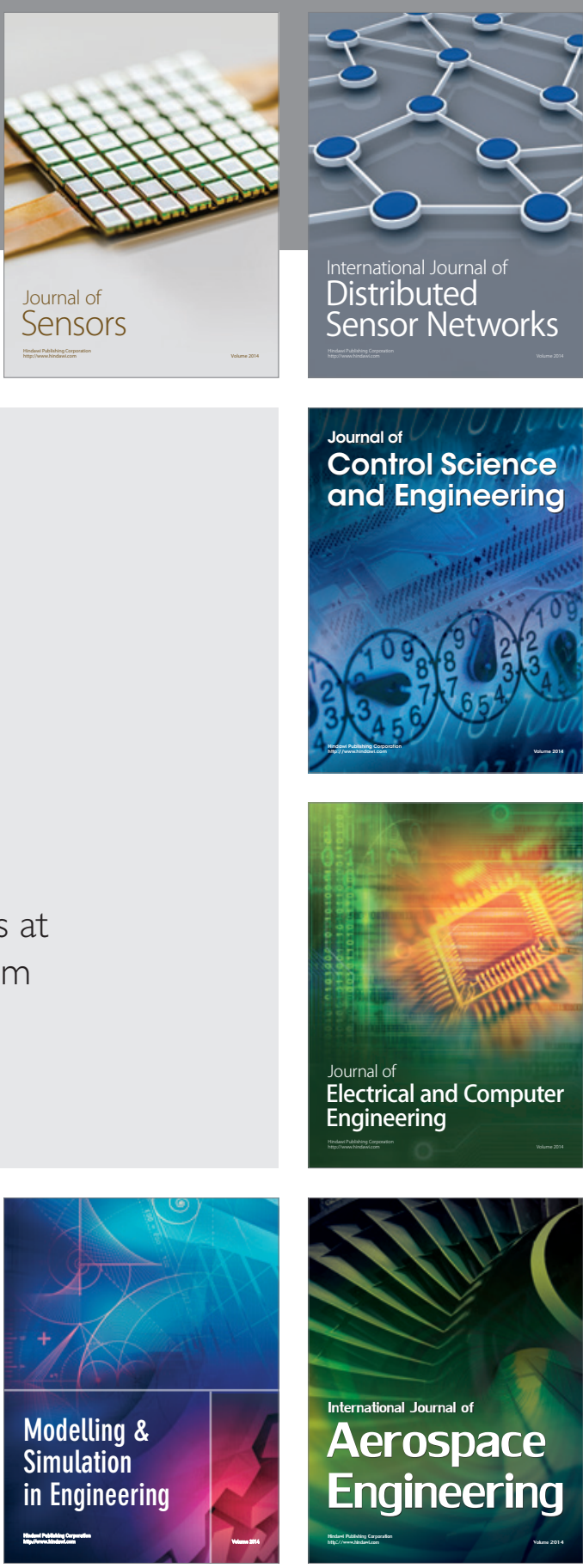

International Journal of

Distributed

Sensor Networks

$-$

Joumal of

Control Science

and Engineering
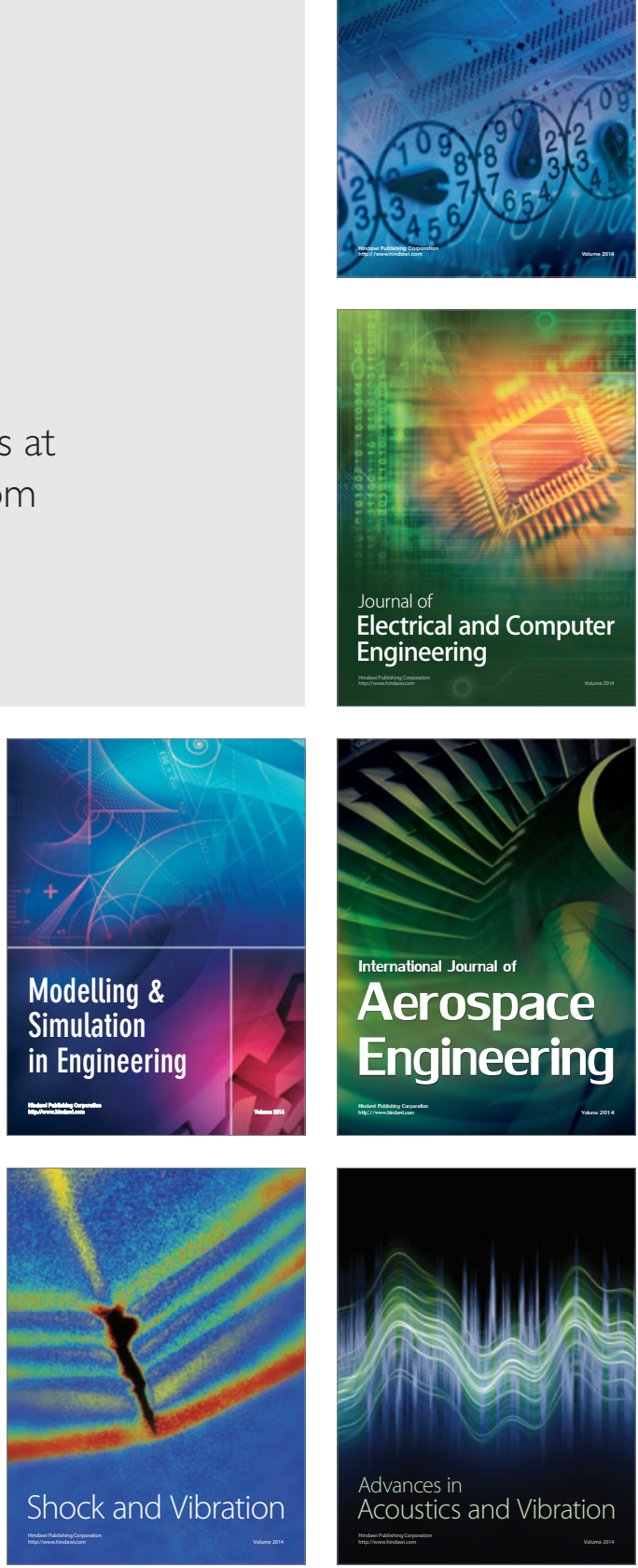